\title{
O ESTUDO DO MOVIMENTO CONSIDERANDO ASPECTOS MATEMÁTICOS E HISTÓRICOS VISANDO ÀS COMPREENSÕES DA AÇÃO LOCAL E DA AÇÃO À DISTÂNCIA.
}

\author{
Jonathan Cedraz Rios'; Milton Souza Ribeiro Miltão ${ }^{2}$ \\ 1. Bolsista PROBIC/UEFS, Graduando em Bacharelado em Física, Universidade Estadual de Feira de Santana, e-mail: \\ jonathanrioos13@gmail.com, \\ 2. Orientador, Departamento de Física, Universidade Estadual de Feira de Santana, e-mail: miltaaao@gmail.com
}

PALAVRAS-CHAVE: Física de Campos; Ação à Distância; Ação Local.

\section{INTRODUÇÃO}

Para desenvolver esse trabalho já havíamos estudado o conceito de ação local bem como o de ação à distância, através de uma abordagem histórica e matemática. No desenvolver desse projeto tendo esses conceitos entendidos e fixados, partimos para entender quais implicações na descrição do movimento, principalmente em seu caráter dinâmico onde buscamos entender qual o causador ou a causa do movimento.

Buscando o entendimento das implicações desses conceitos através de trabalhos como o da mecânica newtoniana principalmente nos processos interativos entre corpos, o estudos realizados por Coulomb, Oersted, Weber entre outros sobre os fenômenos elétricos e magnéticos, assim como o processo de unificação das interações eletromagnéticas, que desencadeou no surgimento do conceito de campo eletromagnético nos trabalhos de Maxwell, que possibilitou a compreensão da luz como resultado da propagação de ondas eletromagnéticas.

A partir da aplicação das transformações de Galileu nos fenômenos eletromagnéticos vimos quais implicações levaram Einstein na elaboração da sua teoria da relatividade, onde a estrutura do espaço e do tempo é totalmente alterada em relação ao ponto de vista newtoniano que prever um espaço e um tempo absoluto. E com isso vemos quais resultados obtemos a respeito da interação gravitacional de objetos massivos com a luz que se propaga como uma onda eletromagnética, sempre buscando entender esses conceitos do ponto de vista da ação local, tendo como agente mediador a ação do campo gravitacional resultante do processo interativo entre dois objetos massivos.

\section{MATERIAL E MÉTODOS OU METODOLOGIA (ou equivalente)}

Na primeira etapa do trabalho foi realizados estudos de aprofundamento do fenômeno movimento e a compreensões de questões como: o referencial, as forças agindo sobre o sistema entre outros conceitos, isso a partir de textos clássicos que tratam o assunto. Foram discutidos os problemas para um a perfeita assimilação de tais conteúdos. A evolução do programa de estudos foi acompanhada por resoluções de exercícios e discussões de forma aberta, na forma de seminários, e textos produzidos ao fim de cada bloco de conteúdo. Juntamente a essas fases do desenvolver do trabalho foi conciliada estudos de artigos científicos que abordam essa problemática, possibilitando uma compreensão do conceito de movimento com noções históricas e matemáticas, que possibilitaram o aprofundamento do estudo em Física de Campos.

RESULTADOS E/OU DISCUSSÃO (ou Análise e discussão dos resultados) 
Um papel de grande importância nos trabalhos desenvolvidos por Newton foi quando se dispôs a estudar os processos interativos entre os corpos que resultou na lei da gravitação universal, e com isso surge à ideia de ação à distância onde as interações ocorrem de forma instantânea sem intervenção de algum meio ao redor dos corpos ou qualquer agente que intermedeie. Essa visão de ação à distância exerceu influencia em outras áreas como, por exemplo, no eletromagnetismo quando Coulomb, Ampère e Weber pesquisavam sobre os fenômenos elétricos e magnéticos.

A relevância apresentada pelo trabalho de Newton e sua influencia exercida nessa época talvez seja a possível explicação da forte influencia exercida pela sua concepção de ação à distância nos processos interativos. Mas ainda havia desconforto por parte de muitos, essa proposta a cerca dos processos interativos através da ação à distância, apesar de conduzirem a resultados satisfatórios, sentiam a ausência de uma explicação física para a forma que os corpos exerciam força uma sobre os outros, os questionamentos resultantes dessas discussões sempre direcionavam para a existência de uma atmosfera que rodeava os objetos e talvez dessem conta dos processos interativos (Rocha, 2009).

No século XIV, já se conhecia que o processo de transmissão de informação em um fluido seria através das partes do mesmo, essa informação pode ser transmissão de calor, vibração de moléculas de um meio como o ar propagando o som, propagação de uma onda ao longo de uma corda ou na superfície de um lago. Esse processo pode ser visto como sendo uma ação local onde a informação é transmitida pelas partes do meio com uma velocidade finita.

Maxwell conhecendo experimentos realizados por Faraday e seu conceito de linhas de força, bem como um calculo realizado por Lord Kevin onde ele aplica equações utilizadas na eletrostática para propor uma solução para problemas de transferência de calor entre corpos (Rocha, 2009), inicia-se o questionamento da possibilidade da transmissão de interações em processos elétricos e magnéticos são através de porções contiguas do meio ao redor dos corpos carregados, como essa interação estaria propagando-se em um meio, Maxwell retoma a ideia do éter, elemento que constituía a quinta essência como previa a teoria aristotélica.

Essa necessidade de um meio como agente transmissor o faz introduzir o conceito de campo em seu trabalho. Têm-se um par de cargas puntiformes q, o campo gerado por ambas as cargas irá exercer uma aceleração mútua, onde a função matemática que descreverá esse campo terá uma dependência espacial e temporal, no caso do campo elétrico $\mathbf{E}(\mathbf{r}, \mathbf{t})$, esse aspecto nos faz perceber do por que tratarmos o campo como uma agente local por permitir a interação através das partes do meio (Jr, 2008). Se a função matemática que descreve o campo elétrico passar a não só variar espacialmente, mas também variar com o tempo irá resultar numa dependência mútua dela com a função que descreve o campo magnético $\mathbf{B}(\mathbf{r}, \mathbf{t})$, onde a partir da síntese de quatro equações por Maxwell, a relação entre campos elétricos e magnéticos resultarão na propagação de uma onda eletromagnética.

Retomando algumas considerações sobre Newton em seu livro "Princípio Matemáticos da Filosofia Natural", ele introduz os conceitos de tempo, espaço e movimento absolutos. Para ele o espaço sendo absoluto existiria independente de qualquer ação externa, estando ele presente em todo local independente de que se tenha algo contido nele. O tempo absoluto segundo sua visão transcorria por sua própria natureza (Assis, 2006). Antecessor de Newton, Galileu utiliza um princípio de relatividade dos movimentos garantindo a independência dos movimentos em cada um dos referenciais, gerando o princípio da relatividade galileana. Ao aplicar os resultados da relatividade galileana na teoria eletromagnética de Maxwell, apresentou-se uma inconsistência justamente no fato das invariâncias das leis físicas em diferentes referenciais inerciais, pois apresentam interpretações diferentes para o mesmo fenômeno em referenciais inerciais distintos (Wolff, 2005). 
Disso surge o questionamento de Einstein, seria a teoria eletromagnética ou o principio da relatividade galileana, que está por trás da razão dessa inconsistência, ele optou e demonstrou em seu artigo em 1905, sobre a relatividade restrita que a inconsistência estaria na relatividade galileana. $\mathrm{O}$ artigo que trata da relatividade restrita, publicado por Einstein foi esclarecedor, deixando de lado o questionamento levantado na época de que a luz sendo uma onda eletromagnética que necessitaria de um meio para sua propagação. Einstein propõe que as observações feitas em referenciais distintos alteram a descrição de uma mesma sequencia de eventos que é definido como uma ocorrência que tem como característica valores definidos de posição e tempo (Young, 2008).

O tratamento feito por Einstein para a teoria da relatividade que trás conceitos onde deixamos de lado o espaço e o tempo absoluto newtoniano, separados um do outro e independentes que agora passam a constitui o espaco-tempo, onde o tempo em referenciais inerciais distintos sofre uma dilatação temporal e os objetos sofrem uma contração de seu comprimento. O tratamento de Einstein feito para a relatividade restrita trata apenas para referencias inerciais, quando temos referenciais não inerciais precisamos do princípio de equivalência para entender questões, como acontece os processos interativos. No princípio de equivalência um referencial acelerado uniformemente equivale a um campo gravitacional constante, ou seja, digamos que um objeto em movimento tenha uma aceleração $g$, igual a aceleração resultante de um corpo em queda livre na Terra, esse objeto acelerado produz um campo gravitacional igual o da Terra, e assim objetos próximos a ele irão interagir com o campo gerado por ele.

\section{CONSIDERAÇÕES FINAIS (ou Conclusão)}

A transição da ação à distância para a ideia de linhas de força proposta por Faraday, e logo após a transição de linhas de força para um fluido que permeia todo espaço, que resultou no surgimento do conceito de campo, suprir a necessidade de um meio para transmissão de processos interativos que nos possibilitou a conclui que em processos interativos temos uma força que é transmitida por partes de um meio contíguo, sendo definido esse processo interativo como uma ação local ou ação mediada. Na relatividade de Einstein temos um exemplo de ação desse tipo em que a luz é curvada ao passar próximo a objetos massivos que deformam a estrutura do espaço-tempo, e assim como no caso onde temos partículas interagentes que resultam em campos elétricos e magnéticos na teoria eletromagnética de Maxwell, esses objetos massivos ao interagirem entre si resulta no campo gravitacional. Hoje sabemos que em um processo de interação entre dois buracos negros foi possível fazer a detecção de ondas gravitacionais, temos que a teoria da relatividade geral de Einstein do ponto de vista da ação do campo gravitacional é vista como uma ação mediada, uma ação local onde a interação entre as massas resulta no campo gravitacional, mas diferente das interações de Maxwell resulta apenas no processo de atração entre os corpos o que faz o campo gravitacional da Terra ou do Sol, por exemplo, atrai corpos ou objetos para seu centro de massa.

Apesar de toda teoria que parte do eletromagnetismo de Maxwell até a teoria da relatividade geral de Einstein descrever os processos interativos a partir da visão da ação local, o entendimento via ação à distância não é tida ainda como descartada, pois além de dá conta da descrição de interações entre partículas carregadas eletricamente interagindo ou no caso da teoria da gravitação de Newton duas massas interagindo, existem comprovações na mecânica quântica que descrevem pares de partículas emaranhadas, em que o processo de interação entre elas é tido como uma ação á distância não abordamos essa discussão nesse relatório, mas deixo aqui como perspectivas futuras de continuidade da pesquisa. 


\section{REFERÊNCIAS}

JR, O. P. Filosofia da Física Clássica. SÃO PAULO: [s.n.].

ROCHA, J. F. M. O conceito de " campo " em sala de aula - uma abordagem históricoconceitual. Revista Brasileira de Ensino de Física, v. 1604, p. 1-17, 2009.

WOLFF, J. F. S. Relatividade : a passagem do enfoque galileano para a visão de Einstein. In Textos de apoio ao professor de física, v. 16, n. 5, 2005.

YOUNG, H. D. F. R. A. Física IV Ótica e Física Moderna. 12a ed. SÃO PAULO: [s.n.]. ASSIS E PESSOA.; "Experimento do Balde e Espaço Absoluto: O espaço e o tempo são absolutos ou relativos?". Filosofia da Física Clássica cap. IV. USP, 2006. 